\title{
To share or not to share, the dilemma is going to be solved
}

\author{
Domenico Prisco $^{1}$ - Pietro Amedeo Modesti ${ }^{1}$
}

Published online: 27 June 2016

(C) SIMI 2016

The International Committee of Medical Journal Editors (ICMJE) has recently formulated a proposal to meet the growing consensus to responsibly share data generated by interventional clinical trials [1] and encourages feedback by 18 April 2016. ICMJE defines a clinical trial as "any research project that prospectively assigns people or a group of people to an intervention, with or without concurrent comparison or control groups, to study the cause and effect relationship between a health-related intervention and a health outcome" [2]. The ICMJE proposes to require authors to share with others; the deidentified individual-patient data (IPD) underlying the results presented in the article not later than 6 months after publication, as a condition of consideration for publication. Should the authors plan to publish in ICMJE member journals (or nonmember journals that choose to follow these recommendations); the data sharing plan is to be defined before beginning patient enrolment when the clinical trial is registered to existing platforms (such as http://www.clin icaltrials.gov, http://www.eudraCT.ema or similars), [1]. To promote a wide discussion within the community of clinical scientists, institutional review boards, and commercial and independent trial sponsors, the ICMJE chose to defer for 1 year implementation of the requirement and to open a forum for those who want to improve the proposal, with a particular emphasis on the conditions for the actual release by the original authors of the individual-patient data

Pietro Amedeo Modesti

pa.modesti@unifi.it

Domenico Prisco

domenico.prisco@unifi.it

1 Department of Experimental and Clinical Medicine, University of Florence, Florence, Italy and their secondary use. This editorial conveys the current opinion of Internal and Emergency Medicine, and welcomes the opinions of readers to contribute to the ICMJE proposal.

In recent years, individual, patient-level clinical trial data sharing generated debate in the research community evoking concerns among investigators, journals, patients, and sponsors. On the side of researchers, a main concern is the possible contribution to the creation of a new class of researchers which some front line investigator has characterized as "research parasites" [3]. People who did not spent years of their life with the design, execution, and attempting to sell the results to a high-level journal, might be allowed to conduct their analyses and disseminate their findings even conflicting with what has just been posited by the original investigators. However, growing evidence is showing that there are many sets of data from clinical trials that are never published or which give rise to only a single paper [3]. The growing journal's demand of data sharing is an opportunity to stimulate a cultural change necessary to modify this researcher's view.

The Ebola crisis, and the more recent global emergency caused by the Zika virus, highlighted the crucial issue of sharing with public media about the scientific information described in a paper or a letter to the editor that has been not yet published. A preliminary communication to the public media may be warranted when the paper or letter describes major therapeutic advances, public health hazards, or serious adverse effects of drugs, biological products, or medical devices. The World Health Organization (WHO) calls on all journals to never be a hindrance when timelines for information sharing are critical. Representatives from major biomedical journals who attended a WHO Consultation in September 2015 agreed with this position. The ICMJE adopts the World Association of Medical 
Editors' definition of editorial freedom, which holds that Editors-in-Chief have full authority over the entire editorial content of their journal and the timing of publication of that content. The reporting should thus be discussed with and agreed upon by the editor in advance when possible.

The patient's side is even more complex. First, the need to avoid the possibility of identifying individual trial participants is well recognized. This goal can be achieved by making anonymous individual records of the conventional clinical trials. Linkage of clinical trials data to administrative database gave new insights in the search of strategies for cancer prevention [4]. However, the possibility of de-identifying trial participants in the Big Data era is challenging. Massive data collections derived from millions of daily interactions within the health care system are increasingly available. However, from the viewpoint of health outcome determinants, almost $60 \%$ of data (i.e. behavioural, socioeconomic, and environmental) are rarely captured by medical records [5]. The possibility to link data on physical activity, healthy behaviours, and weight captured by mobile health devices (apps) and wireless technologies with information from medical records is now leading to the production of new health-based high volume data (Big Data) which have to be integrated into research and clinical practice approaches to prevention [5]. Mobile health technology has the potential to deal with a pressing problem in adherence to prescribed regimens (treatment compliance), and to reach people when they are not patients (prevention). There is justified enthusiasm for harnessing Big Data from cell phones, geospatial location, and biological real-time monitoring of health conditions to improve health and disease management, although privacy is challenged. Users of mobile apps and Web sites authorize data sharing by clicking "I agree" on data use agreements, but such permission does not meet the standards for consent for research. Failure to address the digital divide and to ensure privacy may enhance public distrust and exacerbate healthcare inequities.

The position of sponsors is often clear, and the efforts of industries must be acknowledged. In 2013, GlaxoSmithKline (GSK) launched a cloud-based system for sharing clinical trial data [6]. The project has been joined by a list of other pharmaceutical companies (Astellas, Bayer, Boehringer Ingelheim, Lilly, Novartis, Roche, Sanofi, Takeda, UCB, and ViiV Healthcare), and more than 1200 studies are now available. Similarly, the cooperation of Medtronic with the Yale University resulted the Yale Open Data Access (YODA) Project [7] to allow access to clinical trial data for independent reanalysis. Yale and Medtronic have then been joined by Janssen (Johnson \& Johnson), and currently, YODA has 80 clinical trials available.

The ICMJE proposal is thus now supported from many sectors of society. A feeling of intolerance is now growing in the public opinion, regarding the possibility that commercial interests can afford to hide information on health [8]. Likewise, the growing industry recognition of this new reality is now materialized in sound initiatives. The road to a new cultural view seems to be open.

\section{Compliance with ethical standards}

Conflict of interest The authors declare that they have no conflict of interest.

\section{Financial disclosure None.}

Statement of human and animal rights This article does not contain any studies with human participants or animals performed by any of the authors.

Informed consent None.

\section{References}

1. Taichman DB, Backus J, Baethge C, Bauchner H, de Leeuw PW, Drazen JM, Fletcher J, Frizelle FA, Groves T, Haileamlak A, James A, Laine C, Peiperl L, Pinborg A, Sahni P, Wu S (2016) Sharing clinical trial data: a proposal from the International Committee of Medical Journal Editors. Lancet 387(10016):e9-11. doi:10.1016/S0140-6736(15)01279-9

2. International committee of medical journal editors. Recommendations for the conduct, reporting, editingand publication of scholarly work in medical journals. http://www.icmje.org/icmjerecommendations.pdf. Accessed 1 June 2016

3. Longo DL, Drazen JM (2016) Data Sharing. N Engl J Med 374(3):276-277. doi:10.1056/Nejme1516564

4. Drew DA, Cao Y, Chan AT (2016) Aspirin and colorectal cancer: the promise of precision chemoprevention. Nat Rev Cancer 16(3):173-186. doi:10.1038/nrc.2016.4

5. Antman EM, Benjamin EJ, Harrington RA, Houser SR, Peterson ED, Bauman MA, Brown N, Bufalino V, Califf RM, Creager MA, Daugherty A, Demets DL, Dennis BP, Ebadollahi S, Jessup M, Lauer MS, Lo B, MacRae CA, McConnell MV, McCray AT, Mello MM, Mueller E, Newburger JW, Okun S, Packer M, Philippakis A, Ping PP, Prasoon P, Roger VL, Singer S, Temple R, Turner MB, Vigilante K, Warner J, Wayte P (2015) Acquisition, analysis, and sharing of data in 2015 and beyond: a survey of the landscape a conference report from the American Heart Association Data Summit 2015. J Am Heart Assoc 4(11):e002810. doi:10.1161/JAHA.115.002810

6. Clinical Study Data Request.com. https://clinicalstudydatarequest. com. Accessed 1 June 2016

7. The Yale University Open Data Access (YODA) Project. http:// yoda.yale.edu. Accessed 1 June 2016

8. Loder E (2013) Sharing data from clinical trials: where we are and what lies ahead. BMJ 347:f4794. doi:10.1136/bmj.f4794 